\title{
Prognostic importance of ventricular extrasystoles in acute myocardial infarction
}

\author{
S. TALBOT \\ M.B., B.S., M.R.C.P. \\ Sheffield Royal Infirmary, Sheffield
}

\begin{abstract}
Summary
Ventricular arrhythmias were recorded in 233 patients in a prospective study of patients with acute myocardial infarction. In over $95 \%$ of patients antiarrhythmic therapy was not given until the onset of ventricular tachycardia, ventricular fibrillation, or persistent idioventricular rhythm. There was a mortality of $18 \%$ during the patients' stay in hospital. The most important features of ventricular ectopic activity, which preceded these severe ventricular arrhythmias in the first $48 \mathrm{hr}$, were multiformity, variation of coupling intervals of $\geqslant 0.1 \mathrm{sec}$, the $R$-on- $T$ phenomenon, double ventricular extrasystoles and ventricular bigeminy. The number of single ventricular extrasystoles per minute was related to the probability of these severe ventricular arrhythmias but to a lesser degree. It was found that if all the patients with the first two prognostic features were removed, the number of single ventricular extrasystoles was not of significant import and the other features were less important.

Three-quarters of the severe arrhythmias occurred in the first $24 \mathrm{hr}$ and during this period $60 \%$ were preceded by either multiform ventricular extrasystoles or extrasystoles with variable coupling. The importance of these findings in relation to prophylactic therapy is discussed.
\end{abstract}

\section{Introduction}

Ventricular fibrillation and ventricular tachycardia are important causes of mortality and morbidity following acute myocardial infarction. The introduction of coronary care units has facilitated early treatment of ventricular arrhythmias with resultant saving of life (Pentecost and Mayne, 1968). More recently, physicians have attempted to prevent these arrhythmias by prophylactic therapy (Lown et al., 1967). Such prophylaxis may be universal or selective, and usually this therapy is given to patients thought to be at risk (Bennet, Wilner and Pentecost, 1970). Various parameters of ventricular

Present address: Division of Cardiovascular Disease, Royal Postgraduate Medical School, Hammersmith Hospital, Du Cane Road, London W12 0HS. extrasystolic activity have been described as dangerous and indications for therapy (Lown et al., 1967). However, the prognostic value of these features has not been adequately evaluated. This was the aim of the present prospective study.

\section{Method}

From January 1974 to November 1974 inclusively, 429 patients suspected of having myocardial infarction were admitted to the coronary care unit at the Sheffield Royal Infirmary. The diagnosis was confirmed in 269 patients by the electrocardiogram and/or serum enzyme tests. The electrocardiographic criteria of infarction were based on those of Blackburn et al. (1960), and included all codings Class I $(\mathrm{a}-\mathrm{g})$, Class II $(\mathrm{a}-\mathrm{g})$ associated with evolutionary ST segment and $T$ wave changes of acute injury. Class IIh, Class III (a-c), and Class V (1-3) codings were only included if there were associated enzyme changes together with a history of acute anginal chest pain. Patients with left bundle branch system block were included only if there were associated enzyme changes and a history of acute anginal chest pain. The enzyme tests and the normal limits of enzyme levels were as described by Goldberg and Winfield (1972). Three enzyme levels on consecutive days were sent for aspartate aminotransferase (GOT; normal limits 5-40 i.u./l), alanine aminotransferase (GPT; normal limits 50-30 i.u./l), $\alpha$-hydroxybutyrate dehydrogenase (HBD; normal limits 30-200 i.u./l), and creatine phosphotransferase (CPK; normal limits 15-70 i.u./1). Abnormal levels of two of the tests GOT, CPK or HBD, and normal levels of GPT were considered positive for infarction.

All patients were monitored for at least $48 \mathrm{hr}$ and the nursing staff recorded the number of extrasystoles per minute every hour. If at these times the number of ventricular extrasystoles was $>1$ per minute, a 1-min electrocardiographic recording was performed and this was repeated at 6-hr intervals. Similar observations were made at other times if ventricular extrasystoles appeared or increased in number. Recordings of ventricular tachycardia, 
ventricular fibrillation and idioventricular rhythm and any other supraventricular arrhythmias were taken as necessary.

A clinical assessment of each patient was made on admission and at least daily thereafter. Daily 12 lead electrocardiograms and at least one chest radiograph were performed. All patients were followed up until their discharge or death. The policy is to discharge patients from the tenth day onwards after infarction.

Anti-arrhythmic therapy was not used routinely but was given for ventricular tachycardia or following an episode of ventricular fibrillation. Electrocardiographic criteria for ventricular tachycardia were 3 ventricular extrasystoles in a row separated from each other by $<600 \mathrm{msec}$. If there were $\geqslant 600 \mathrm{msec}$ between such extrasystoles the rhythm was considered idioventricular. Extrasystoles were considered ventricular on the usual criteria (Lipman and Massie, 1965; Talbot, 1973). Differentiation from aberrant conduction was based on the criteria of Marriott (Sandler and Marriott, 1965) but when in doubt the rhythm was considered supraventricular.

Treatment varied depending on the physician concerned, but usually lignocaine was given as a bolus of $100 \mathrm{mg}$ followed by an infusion of at least $1 \mathrm{mg} / \mathrm{min}$, to suppress ventricular extrasystoles or at least repetitive activity. After $12-24 \mathrm{hr}$ procainamide $500 \mathrm{mg}$ every $6 \mathrm{hr}$ was given, and $12 \mathrm{hr}$ after this, intravenous lignocaine was discontinued. Procainamide was continued for $48 \mathrm{hr}$ onwards. The patients were removed from the study after antiarrhythmic therapy had been started. Because of this, some patients were studied only on the first day after infarction. Other patients who were admitted late to the coronary care unit, were studied only in the second $24 \mathrm{hr}$ after myocardial infarction.

The parameters of ventricular extrasystolic activity which were studied were as follows:

(1) The R-on-T phenomenon (Smirk and Palmer, 1960).

(2) Multiformity of single extrasystoles on a 1-min electrocardiographic recording. Comparison of records often demonstrated differences in the form of extrasystoles but since the dominant rhythm sometimes showed changes in wave-form these differences have not been included.

(3) The relationship of extrasystoles to the T wave.

(4) Variation in the coupling intervals of ventricular extrasystoles by $\geqslant 100 \mathrm{msec}$ on a 1-min electrocardiographic recording. If there were multiform extrasystoles only variation of one form was accepted (Talbot, 1973).

(5) Double ventricular extrasystoles if they were separated by $600 \mathrm{msec}$ or less.

(6) Ventricular bigeminy or alternation (Schamroth, 1966).
(7) Maximum number of single ventricular extrasystoles in any one minute of any one day: (a) $\geqslant 20$ extrasystoles; (b) $\geqslant 15<20$ extrasystoles; (c) $\geqslant 10$ $<15$ extrasystoles; (d) $\geqslant 5<10$ extrasystoles; (e) isolated extrasystoles or extrasystoles of $<5$ per minute; (f) extrasystoles were not observed.

All arrhythmias were related to the time after infarction and its location (Blackburn et al., 1960). Although it was relatively easy to date infarction, accurate timing was based on the clinical history and examination in conjunction with the results of three serum enzyme tests on consecutive days (Goldberg and Winfield, 1972). If these were conflicting, a further history was taken to elucidate if and when one or more infarctions had occurred.

\section{Results}

Two hundred and sixty-nine patients with acute myocardial infarction were admitted to the coronary care unit and monitored for $48 \mathrm{hr}$ (of these, seventeen were re-admitted and therefore appeared twice in the study). There were forty-eight deaths $(18 \%)$ within 10 days after infarction. There were no deaths that could be ascribed to arrhythmias during the first $48 \mathrm{hr}$. However, thirty-one patients died on the coronary care unit from either severe left ventricular failure or cardiogenic shock. Although these patients often had arrhythmias they have not been reportedo since therapy for these arrhythmias would not have saved life. In addition, a further five patients who were paced for heart block on the day of admission have been excluded. The results of 233 patients have been presented.

Of these 233, three were admitted on the second day after infarction, four had immediate therapy because of ventricular fibrillation on admission and two had $\geqslant 20$ extrasystoles on admission for which treatment was given. Details of the arrhythmias in the remaining 224 patients have been presented in Table 1. In this table are shown the number of patients with any premonitory form of arrhythmia who subsequently developed short paroxysms of ventricular tachycardia (PVT), ventricular tachycardia which was sustained for at least $1 \mathrm{~min}$, ventricular fibrillation or idioventricular rhythm, and these will subsequently be called severe ventricular arrhythmias. Many of these arrhythmias occurred in the same patient, but the premonitory arrhythmias have been listed in order of importance. A similar analysis was performed for severe ventricular arrhythmias occurring on the second day after infarction (Table 2). Only 192 patients were studied on the second day; twenty-nine were removed from the study because of severe ventricular arrhythmias for which they received treatment, including three who were treated for idioventricular rhythm alone, one was discharged early from the coronary care unit 
TABLE 1. Arrhythmias preceding idioventricular rhythm, ventricular tachycardia and ventricular fibrillation (first day)

\begin{tabular}{|c|c|c|c|c|c|c|}
\hline Preceding arrhythmias & $\begin{array}{l}\text { No. of } \\
\text { patients }\end{array}$ & $\begin{array}{l}\text { No. with idio- } \\
\text { ventricular } \\
\text { rhythm }\end{array}$ & $\begin{array}{l}\text { No. with } \\
\text { paroxysmal } \\
\text { ventricular } \\
\text { tachycardia }\end{array}$ & $\begin{array}{l}\text { No. with } \\
\text { sustained } \\
\text { ventricular } \\
\text { tachycardia }\end{array}$ & $\begin{array}{l}\text { No. with } \\
\text { ventricular } \\
\text { fibrillation }\end{array}$ & $\begin{array}{l}\text { Total no. } \\
\text { with severe } \\
\text { arrhythmias } \\
\text { (percentage in } \\
\text { parentheses) }\end{array}$ \\
\hline Multiform extrasystoles & 44 & $13^{*}$ & $16^{*}$ & 1 & 2 & $27^{*}(61 \cdot 4)$ \\
\hline Variable coupling & 47 & $16^{*}$ & $11^{*}$ & 4 & 4 & $28 *(59 \cdot 6)$ \\
\hline $\mathbf{R}$-on-T phenomenon & 24 & 2 & 3 & 2 & 2 & 7 (29) \\
\hline Double ventricular extrasystoles & 21 & 9 & 4 & 0 & 1 & $12 \dagger(57 \cdot 1)$ \\
\hline $\begin{array}{l}\text { Ventricular bigeminy and } \\
\text { extrasystoles } \geqslant 20 / \mathrm{min}\end{array}$ & 22 & 8 & 4 & 1 & 0 & $11 \dagger(50)$ \\
\hline $\begin{array}{l}\text { Ventricular extrasystoles } \\
\geqslant 15<20 / \mathrm{min}\end{array}$ & 5 & 2 & 0 & 0 & 1 & 3 \\
\hline $\begin{array}{l}\text { Ventricular extrasystoles } \\
\quad \geqslant 10<15 / \mathrm{min}\end{array}$ & 8 & 2 & 0 & 0 & 2 & 3 \\
\hline $\begin{array}{l}\text { Ventricular extrasystoles } \\
\geqslant 5<10 / \mathrm{min}\end{array}$ & 14 & 1 & 3 & 2 & 1 & 3 \\
\hline Ventricular extrasystoles $<5 / \mathrm{min}$ & 112 & 20 & 15 & 3 & 1 & 27 \\
\hline No ventricular extrasystoles & 60 & 4 & 2 & 1 & 1 & 7 \\
\hline Total number & 224 & 35 & 26 & 9 & 7 & $64(28 \cdot 6)$ \\
\hline
\end{tabular}

* Significant difference from that expected $\left(\chi^{2}\right.$ test, $\left.P<0.01\right)$; + Significant difference from that expected $\left(\chi^{2}\right.$ test, $\left.P<0.02\right)$.

TABLE 2. Arrhythmias preceding idioventricular rhythm, ventricular tachycardia and ventricular fibrillation (second day)

\begin{tabular}{|c|c|c|c|c|c|c|}
\hline Preceding arrhythmias & $\begin{array}{l}\text { No. of } \\
\text { patients }\end{array}$ & $\begin{array}{l}\text { No. with idio- } \\
\text { ventricular } \\
\text { rhythm }\end{array}$ & $\begin{array}{l}\text { No. with } \\
\text { paroxysmal } \\
\text { ventricular } \\
\text { tachycardia }\end{array}$ & $\begin{array}{l}\text { No. with } \\
\text { sustained } \\
\text { ventricular } \\
\text { tachycardia }\end{array}$ & $\begin{array}{l}\text { No. with } \\
\text { ventricular } \\
\text { fibrillation }\end{array}$ & $\begin{array}{l}\text { Total no. } \\
\text { with severe } \\
\text { ventricular } \\
\text { arrhythmias } \\
\text { (percentages in } \\
\text { parentheses) }\end{array}$ \\
\hline Multiform extrasystoles & 23 & 3 & 4 & 1 & 1 & $6(26 \cdot 1)$ \\
\hline Variable coupling & 32 & 7 & 7 & 1 & 1 & $13(40 \cdot 6)$ \\
\hline R-on-T phenomenon & 5 & 2 & 1 & 1 & 2 & 5 \\
\hline Double ventricular extrasystoles & 15 & 3 & 3 & 1 & 0 & 8 \\
\hline $\begin{array}{l}\text { Ventricular bigeminy and extra- } \\
\text { systoles } \geqslant 20 / \mathrm{min}\end{array}$ & 16 & 4 & 2 & 1 & 0 & 6 \\
\hline $\begin{array}{l}\text { Ventricular extrasystoles } \\
\geqslant 15<20 / \mathrm{min}\end{array}$ & 4 & 0 & 0 & 0 & 0 & 0 \\
\hline $\begin{array}{l}\text { Ventricular extrasystoles } \\
\quad \geqslant 10<15 / \mathrm{min}\end{array}$ & 5 & 1 & 0 & 0 & 0 & 1 \\
\hline $\begin{array}{l}\text { Ventricular extrasystoles } \\
\geqslant 5<10 / \mathrm{min}\end{array}$ & 9 & 1 & 1 & 0 & 0 & 2 \\
\hline Ventricular extrasystoles $<5 / \mathrm{min}$ & 94 & 8 & 5 & 0 . & 1 & $10(10 \cdot 6)$ \\
\hline No ventricular extrasystoles & 59 & 0 & 0 & 0 & 0 & 0 \\
\hline Total & 192 & 13 & 8 & 1 & 2 & $20(10 \cdot 1)$ \\
\hline
\end{tabular}

and the remainder were removed from the study because treatment was given for other reasons.

Multiform ventricular extrasystoles and variable coupling of ventricular extrasystoles were the most frequent warning arrhythmias and they were significantly associated with idioventricular rhythm and paroxysms of ventricular tachycardia, in the first 24 hr after infarction. Other arrhythmias were not significantly associated with any of the severe ventricular arrhythmias. The proximity of ventricular extrasystoles to the $T$ wave was not of significance for extrasystoles following the $T$ wave but the R-on$T$ phenomenon was particularly related to ventricular tachycardia and fibrillation although the numbers were too small for statistical analysis.

Although sustained ventricular tachycardia and ventricular fibrillation are immediate threats to life, idioventricular rhythm and short paroxysms of ventricular tachycardia are not, although: they are usually considered to be severe ventricular arrhythmias. If sustained ventricular tachycardia and ventricular fibrillation (ventricular tachycardia) 


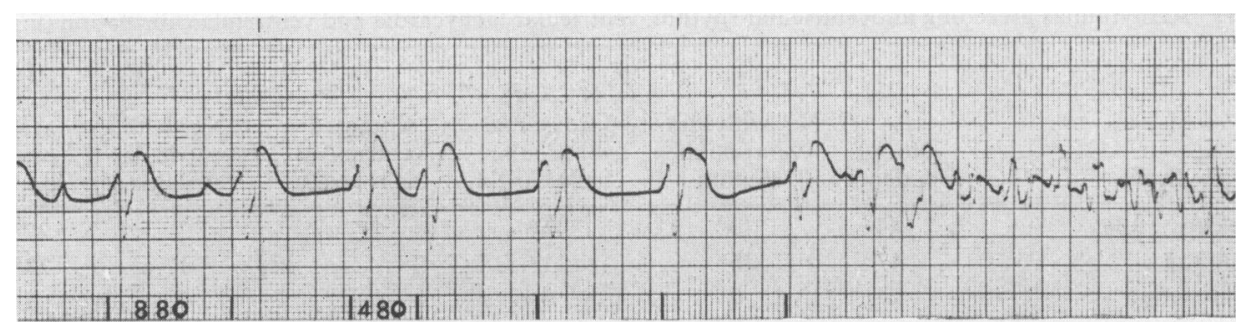

FIG. 1. Irregular idioventricular rhythm in a patient with acute inferior myocardial infarction followed by closely coupled ventricular extrasystoles and then ventricular fibrillation.

fibrillation) alone are considered, then seventeen patients had these arrhythmias on the first day. However, ten of these would still have had ventricular tachycardia/fibrillation even if therapy had been given for the two principal premonitory arrhythmias because in four patients these arrhythmias occurred less than $5 \mathrm{~min}$ before ventricular tachycardia/ fibrillation and in six these features were never observed. On the second day, however, there were only two patients with ventricular tachycardia/ fibrillation. Both of these arrhythmias were preceded by multifocal extrasystoles and/or variable coupling.

Idioventricular rhythm has been described as a benign arrhythmia. However, of thirty-five patients with idioventricular rhythm on the first day, five had paroxysms of ventricular tachycardia, two had sustained ventricular tachycardia and two had ventricular fibrillation. On the second day thirteen patients had idioventricular rhythm; of these, four had paroxysms of ventricular tachycardia, one had sustained ventricular tachycardia and one had ventricular fibrillation. Although this arrhythmia has less significance than multiform extrasystoles or variable coupling it appears to be as significant as double ventricular extrasystoles and ventricular bigeminy, and is certainly more important than the total number of extrasystoles alone (Fig. 1).

The location of infarction in patients with idioventricular rhythm, paroxysms of ventricular tachycardia, sustained ventricular tachycardia and ventricular fibrillation was compared to the location in those without such arrhythmias. Idioventricular rhythm was associated with inferior myocardial infarction $(P<0.01)$ and ventricular tachycardia was associated with anterior myocardial infarction $(P<0.02)$. There was a slight but insignificant association of ventricular tachycardia with septal infarction but the number of patients was small. Paroxysms of ventricular tachycardia and sustained ventricular tachycardia were both associated with anterior infarction. Associations were more marked on the first day after infarction and these are shown in Table 3.
TABlE 3. Association of site of infarction and severe ventricular arrhythmias (first day)

\begin{tabular}{lccc}
\hline & $\begin{array}{c}\text { No. with } \\
\text { arrhythmia }\end{array}$ & $\begin{array}{c}\text { No. without } \\
\text { arrhythmia }\end{array}$ & Total \\
\hline $\begin{array}{l}\text { Ventricular tachycardia } \\
\text { Anterior infarction* }\end{array}$ & 24 & 80 & 104 \\
$\begin{array}{l}\text { No. of patients with } \\
\text { infarction other than } \\
\text { anterior }\end{array}$ & 11 & 118 & 129 \\
$\begin{array}{l}\text { Idioventricular rhythm } \\
\text { Inferior infarction } \dagger \\
\text { No. of patients with } \\
\text { infarction other than } \\
\text { inferior }\end{array}$ & 21 & 67 & 88 \\
\hline
\end{tabular}

* Significantly more patients with anterior infarction and ventricular tachycardia $\left(\chi^{2}=7 \cdot 7, P<0.02\right)$; $\dagger$ significante more patients with inferior infarction and idioventricula rhythm $\left(\chi^{2}=8.4, P<0.01\right)$.

Ventricular arrhythmias were not more frequent in association with left anterior hemiblock. The number of patients with right bundle branch block and left anterior hemiblock (excluding patients with cardiogenic shock or severe cardiac failure) was too small for any significant conclusion to be reached.

There were only a third as many patients with severe ventricular arrhythmias on the second day as on the first. Premonitory arrhythmias were less frequent but were also less significant. Although removal of patients on therapy may have influenced these figures it is probable that the time after infarc-

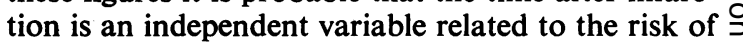
serious arrhythmias.

\section{Discussion}

From this study it can be concluded that moni- o toring of patients for parameters of ventricular $N$ extrasystole activity following acute myocardial in- $\omega$ farction, by nurses on a coronary care unit, is of value. Multiform ventricular extrasystoles and $\varrho$ variable coupling of uniform ventricular extra- $\bar{\Phi}$ systoles were the most significant warnings of severe $\stackrel{?}{+}$ arrhythmias. However, severe arrhythmias were only $\frac{0}{0}$ one-third as frequent on the second day, although $\frac{\vec{D}}{\mathbb{D}}$ 
these premonitory arrhythmias were not decreased proportionately.

The R-on- $\mathrm{T}$ phenomenon, multifocal ventricular extrasystoles and extrasystoles $\geqslant 5$ per minute, double ventricular extrasystoles and bigeminy have all been associated with ventricular fibrillation and ventricular tachycardia (Lown et al., 1967; Lawrie et al., 1968). However, earlier workers have not clearly established the importance of preceding arrhythmias over subsequent arrhythmias and the relative importance of short bursts of ventricular tachycardia, idioventricular rhythm, sustained ventricular tachycardia and ventricular fibrillation (Raftery et al., 1970; Fluck et al., 1967; Chopra et al., 1971). Their studies have not excluded the effects of treatment. Although it has not been possible to eliminate the effect of treatment completely, the author feels that, if anything, departures from the protocol were for the arrhythmias he found to be important, e.g. multiform ventricular extrasystoles. Even if these patients are considered to have had serious arrhythmias without warning arrhythmias the results are not affected significantly. The treatment protocol which was followed, however, made it impossible to assess the importance of bursts of paroxysmal ventricular tachycardia and short bursts of idioventricular rhythm.

This study was based on nursing observations and recordings and short-lasting arrhythmias sometimes will have been missed or wrongly interpreted. Tape recordings may show more arrhythmias but such recordings must be analysed and therefore it is likely that, at present, therapy will be based on immediate interpretation of the rhythm by the nurse and doctor.

Since there were few patients with ventricular tachycardia/fibrillation it is impossible to draw any conclusions about these arrhythmias alone. If all severe ventricular arrhythmias are considered together it does appear that all the usually accepted 'warning arrhythmias' are of value. However, there are frequent associations between the warning arrhythmias. Since it was found that multiform ventricular extrasystoles and variable coupling of extrasystoles are the most sensitive prognostic indicators it is reasonable to compare the significance of the other warning arrhythmias in their absence. From such a comparison it is clear that the number of ventricular extrasystoles per minute is of little significance and the other parameters are of only limited value. However, from this study and other reports (Chopra et al., 1971; Pentecost and Bennet, 1972), the R-on-T phenomenon frequently presages ventricular tachycardia/fibrillation, although not the other arrhythmias. However, its relative infrequency makes it of limited use.

The association of variable coupling and severe ventricular arrhythmias does not indicate that such arrhythmias are parasystolic and that the severe ventricular arrhythmias are automatic in origin. In this study only two patients had parasystole using acceptable criteria (Talbot, 1973; Scherf and Schott, 1953), and other studies have shown that parasystole occurs in less than $5 \%$ of patients with aucte myociardial infarction (Baxter and McGuiness, 1974). The variable coupling was usually non-parasystolic (Talbot, 1973), although some recordings could have been interpreted as intermittent parasystole or parasystole with variable exit block. Such rhythms may be automatic in origin. Idioventricular rhythm is probably automatic in nature and this may explain the strong association between variable coupling and slow idioventricular rhythm. The association between variable coupling and paroxysms of ventricular tachycardia may be for similar reasons, since it has frequently been noted that these tachycardias are slower than $150 / \mathrm{min}$ and are often associated with idioventricular rhythms of $80-100 / \mathrm{min}$. The author has noted transitions from a fast to a slow ventricular rhythm of similar contour, and vice versa. The criteria used to distinguish these arrhythmias are arbitrary and others have had similar experience using different criteria (Clarke and Hamer, 1974; De Soyza et al., 1974).

It has been suggested that ventricular tachycardias after myocardial infarction are usually automatic in the first $28 \mathrm{hr}$ and later may be due to re-entry (Wellens, Lie and Durrer, 1974) and our experience would support this. The author has not seen ventricular or supraventricular tachycardia in the first $48 \mathrm{hr}$ after myocardial infarction with evidence of reciprocation. However, ventricular tachycardia/ fibrillation may be due to associated re-entry since Watanabe, Pamintuan and Dreifus (1973) recently showed how automaticity and re-entry may be due to similar electrophysiological mechanisms.

Do these prognostic arrhythmias help in the practical management of patients with acute myocardial infarction? If prophylactic therapy is to be universally successful it must be applied to all patients during the first $24 \mathrm{hr}$, although after this it would seem of little value for patients without ventricular extrasystoles. However, almost as many patients could be protected by a selective prophylactic policy. If such therapy becomes of proved benefit it could be given to patients with multiform ventricular extrasystoles and/or variable coupling, and/or the R-on- $T$ phenomenon. However, the mortality of this series of patients on a coronary care unit does not suggest that selective therapy without prophylaxis is harmful. Therapy has been suggested for ventricular extrasystoles to improve haemodynamic function (Fluck et al., 1967) but bigeminy is often transient and ventricular extrasystoles are not treated unless they are persistently over $20 / \mathrm{min}$. 
Ventricular tachycardia/fibrillation has often been recorded in the absence of preceding arrhythmias (Pentecost and Bennet, 1972; Wellens et al., 1974; Lie, Wellens and Durrer, 1974). Most of these patients develop these arrhythmias soon after admission to hospital and pre-hospital coronary care may allow time for further preventative measures. Fully automated methods (Yanowitz et al., 1974) may eventually allow significant complex parameters of ventricular extrasystoles to be measured, but in view of the dynamic state after myocardial infarction only the arrhythmias that occur shortly before the onset of ventricular tachycardia/fibrillation will probably be of great prognostic value.

\section{References}

Baxter, R.H. \& McGuiness, J.B. (1974) Comparison of ventricular parasystole with other dysrhythmias after acute myocardial infarction. American Heart Journal, 88, 443.

Bennet, M.A., Wilner, J.M. \& Pentecost, B.L. (1970) Controlled trial of lignocaine in prophylaxis of ventricular arrhythmias complicating myocardial infarction. Lancet, ii, 909.

Blackburn, H., Keys, A., Simonson, E., Rautaharju, P. \& PUnSAR, S. (1960) The electrocardiogram in population studies: a classification system. Circulation, 21, 1160.

Clarke, L.M. \& Hamer, J. (1974) Prognosis of idioventricular rhythm after cardiac infarction. Proceedings of the British Cardiac Society. British Heart Journal, 36, 397.

Chopra, M.P., Thadani, U., Portal, R.W. \& Aber, C.P. (1971) Lignocaine therapy for ventricular ectopic activity after acute myocardial infarction. A double blind trial. British Medical Journal, 3, 668.

De Soyza, N., Bissett, J.K., Kane, J.J., Murphy, M.L. \& DoHerTy, J.E. (1974) Association of accelerated idioventricular rhythm and paroxysmal ventricular tachycardia. American Journal of Cardiology, 34, 667.

Fluck, D.C., Olsen, E., Pentecost, B.L., Thomas, M., Fillimore, S.J., Shillingford, J.P. \& MounSEY, J.P.D. (1967) Natural history and clinical significance of arrhythmias after acute cardiac infarction. British Heart Journal, 29, 170.

GoldberG, D.M. \& Winfield, D.A. (1972) Diagnostic accuracy of serum enzyme assays for myocardial infarction in a general hospital population. British Heart Journal, 34, 597.
LaWrie, D.M., Higgins, M.R., Godman, M.J., Oliver, $\frac{\varrho}{\gtrless}$ M.F., Julian, D.G. \& Donald, K.W. (1968) Ventricular fibrillation complicating myocardial infarction. Lancet, ii, 523.

LIE, K.I., Wellens, H.J. \& DURRER, D. (1974) Characteristics and predictability of primary ventricular fibrillation. European Journal of Cardiology, 1, 379.

LIPMAN, B.S. \& MASSIE, E. (1965) Clinical Scalar Electrocardiography, 5th Edn (Year Book, Chicago 1965).

Lown, B., FAKHro, A.M., Hood, W.B. \& ThorN, G.W.

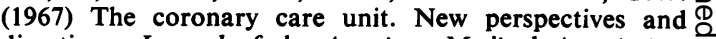
directions. Journal of the American Medical Association, 199, 188.

Pentecost, B.L. \& Bennet, M.A. (1972) Warning of cardiac $\vec{\circ}$ arrest due to ventricular fibrillation and tachycardia. Lancet, i, 1351.

Pentecost, B.L. \& MAYNe, N.M.C. (1968) Results of a general hospital coronary care service. British Medical Journal, 1, 830.

Raftery, E.B., Rehman, M.F., Banks, D.C. \& Oram, S. (1970) Incidence and management of ventricular arrhyth- if mias after acute myocardial infarction. British Heart Journal, 31, 273.

SANDLER, A. \& MARRIOTT, H.J.L. (1965) The differential $\overparen{P}$ morphology of anomalous ventricular complexes of $\overparen{\wp}$ R.B.B.B. in lead VI. Ventricular ectopy versus aberration. 0 Circulation, 31, 551 .

SCHAMroth, L. (1966) Genesis and evolution of ectopic $\overrightarrow{-}$ ventricular rhythm. British Heart Journal, 28, 244.

SCHERF, D. \& SChotT, A. (1953) Extrasystoles and Allied Arrhythmias, 1st edn. Heinemann, London.

SMIRK, F.H. \& PALMER, D.G. (1960) A myocardial syndrome with particular reference to the occurrence of sudden $\rightarrow$ death and of premature systoles interrupting antecedent $\vec{\theta}$ waves. American Journal of Cardiology, 6, 620.

TALBOT, S. (1973) Fixed and variable coupling of ventricula extrasystoles. Cardiology, 58, 118.

Watanabe, Y., Pamintuan J.C. \& Dreifus, L.S. (1973) Role of intraventricular conduction disturbances in ven- $\bar{\partial}$ tricular premature systoles. American Journal of Cardio$\log y, 32,188$.

Wellens, H.J.J., LIE, K.J. \& Durrer, D. (1974) Further observations on ventricular tachycardia as studied by $\overrightarrow{\bar{\sigma}}$ electrical stimulation of the heart. Chronic recurrent $\frac{0}{3}$ ventricular tachycardia and ventricular tachycardia during acute myocardial infarction. Circulation, 49, 647.

Yanowitz, F., Kinias, P., Rawling, D. \& Fozzard, H.A. (1974) Accuracy of a continuous real-time ECG dysrhyth- $\bar{\partial}$ mia monitoring system. Circulation, 50, 65. 